\title{
Projeto Mais Médicos para o Brasil: A experiência pioneira do apoio institucional no Ministério da Educação.
}

\author{
"More Physicians for Brazil Project": The pioneer \\ experience of institutional support by the Ministry of \\ Education.
}

Proyecto Médico Más a Brasil: Una experiencia pionera del apoyo institucionale del Ministerio de la Educación.

Erika Rodrigues de ALMEIDA ${ }^{1}$ Heloísa Germany ${ }^{2}$ Jackeline Gomes Alvarenga Firmiano ${ }^{2}$ Adriano Ferreira Martins ${ }^{2}$

Anderson Sales Dias ${ }^{2}$

RESUMO: O Projeto Mais Médicos para o Brasil (PMMB) foi criado em 2013, em virtude da necessidade de fixar profissionais médicos na Atenção Primária à Saúde e reorientar a formação médica no Brasil. No intuito de fortalecer as ações do PMMB nos Estados, especialmente aquelas relacionadas ao processo de Supervisão Acadêmica dos médicos do PMMB, o Ministério da Educação estruturou uma proposta de apoio institucional (AIMEC), pioneira no âmbito desta Instituição. Os primeiros apoiadores foram contratados em março de 2014, para os estados de Minas Gerais, Bahia, Ceará e Rio Grande do Sul. Este trabalho vem relatar essa experiência, com a discussão sobre os pontos fortes e frágeis desta iniciativa pioneira, na perspectiva de apontar oportunidades de seu fortalecimento e consolidação. O AIMEC tem se apresentado como um novo e interessante modo de gestão e tem sido uma ferramenta valorizada entre os diversos atores do PMMB. Por meio do diálogo e trabalho colaborativo, resultados positivos têm sido observados, o que tem impactado diretamente no aperfeiçoamento do PMMB.

Palavras chave: Atenção Primária à Saúde. Mais Médicos. Apoio Institucional.

ABSTRACT: The More Physicians for BrazilProject (PMMB) was created in 2013 because of

1 Nutricionista sanitarista, mestre em Ciências da Nutrição, Doutoranda em Saúde Pública. Pesquisadora do ISC/ UFBA. Coordenadora-geral de Expansão e Gestão da Educação em Saúde da DDES/SESu/MEC

2 DDES/SESu/MEC

ISSN 1982-8829

Tempus, actas de saúde colet, Brasília, 9(4), 49-66, dez, 2015 
the need to establish health professionals in Primary Health Care and reorient medical education in Brazil. In order to strengthen the actions of PMMB in the States, especially those related to the Academic Supervision process for PMMB's doctors, the Ministry of Education structured an institutional support proposal (AIMEC), a pioneering effort within this Institution. The first supporters were hired in March 2014, in the states of Minas Gerais, Bahia, Ceará and Rio Grande do Sul. This research has been reporting this experience with an active discussion about the strengths and weaknesses of this pioneering initiative, with the objective of pointing out an approach for its strengthening and consolidation. The AIMEC has emerged as a new and interesting way of management and has been a valuable tool between the various participants in the PMMB. Through dialogue and collaborative work, positive results have been observed, which have a direct impact on the improvement of the PMMB.

Key words: Primary Health Care. More Doctors. Institutional Support.

RESUMEN: El Proyecto Más Médicos a Brasil (PMMB) fue creado en 2013 por la necesidad de fijar los profesionales de salud en la Atención Primaria de Salud y reorientar la educación médica en Brasil. Con el fin de fortalecer las acciones de PMMB en los Estados, sobre todo los relacionados con el proceso de Supervisión Académica para los médicos do PMMB, el Ministerio de Educaciónha estructurado una propuesta de apoyo institucional (AIMEC), pionero dentro de esta Institución. Los primeros seguidores fueron contratados en marzo 2014, a los estados de Minas Gerais, Bahia, Ceará y Río Grande do Sul. Este trabajo ha sido la presentación de informes de esta experiencia a la discusión acerca de las fortalezas y debilidades de esta iniciativa pionera, con el fin de señalar las oportunidades de su fortalecimiento y consolidación. El AIMEC se ha convertido en una forma de gestión nuevo e interesante y ha sido una herramienta valiosa entre los diversos actores de PMMB. Através del diálogo y del trabajo colaborativo, se han observado resultados positivos, lo que ha impactado directamente en la mejora de PMMB.

Palabras clave: Atención Primaria Más Médicos. Apoyo Institucional.

\section{INTRODUÇÃO}

A saúde brasileira é organizada e ofertada à população por meio do Sistema Único de Saúde (SUS), o qual é considerado um dos maiores sistemas públicos de saúde do mundo, tendo em vista seu acesso integral, universal e gratuito para toda a população. O SUS foi criado pela Constituição Federal Brasileira em 1988 e atua segundo os princípios de universalidade, integralidade, equidade, regionalização, hierarquização e participação popular. Está organizado em três níveis assistenciais: primário, secundário e terciário, organizados a partir do grau de densidade tecnológica necessário à resolução das necessidades de saúde da população ${ }^{1}$.

No tocante ao primeiro nível assistencial - a Atenção Primária à Saúde (APS) ou Atenção Básica (AB) -, têm sido implementados diversos programas, políticas e iniciativas para garantir a 


\section{$51 / /$}

oferta de cuidados primários à saúde que abarquem ações de promoção à saúde, de prevenção de riscos, doenças e agravos, de cura, de tratamento e de reabilitação.

Dentre as principais estratégias implementadas em prol da APS brasileira destacam-se o Programa de Agentes Comunitários de Saúde (PACS); o Programa Saúde da Família (PSF), tido como estratégia para expandir, qualificar e consolidar a Atenção Básica a partir de uma reorientação do processo de trabalho das equipes de saúde; a reconstrução e o aumento do financiamento da $\mathrm{AB}^{2,3}$; o Programa de Requalificação das Unidades Básicas; a criação dos Núcleos de Apoio à Saúde da Família (NASF) ${ }^{4}$; a criação do novo Sistema de Informação da Atenção Básica (SISAB) a estratégia e-SUS Atenção Básica; o Programa Telessaúde Brasil Redes ${ }^{6}$; o Programa de Melhoria do Acesso e Qualidade da Atenção Básica (PMAQ-AB) ${ }^{7-9}$; a criação do Programa Academia da Saúde; a nova Política Nacional de Alimentação e Nutrição ${ }^{10}$; a Política de Educação Permanente do SUS para os profissionais da AB; o Plano Nacional de Educação Médica; e, mais recentemente, os Programas de Valorização da Atenção Básica (PROVAB $)^{11}$ e o Programa Mais Médicos (PMM) ${ }^{12,13}$.

O PMM foi criado a partir da mobilização de prefeitos em torno da necessidade de fixação de profissionais médicos nos diversos municípios brasileiros, sobretudo em municípios do interior e nas periferias, bem como da necessidade de reorientação da formação médica do Brasil ${ }^{14,15}$. A partir desta mobilização, os Ministérios da Saúde e Educação realizaram estudos sobre o quantitativo de médicos disponíveis para o mercado de trabalho no Brasil, tendo encontrado relação de 1,8 médicos por mil habitantes, quantitativo inferior a diversos países europeus como Portugal (3,9/ mil hab), Espanha (4/mil hab), Reino Unido (2,7/mil hab), Itália (3,5/mil hab) e Alemanha (3,6/mil hab), e latino-americanos como Argentina (3,2/mil hab) e Uruguai (3,7/mil hab) ${ }^{15,16}$.

A partir deste panorama, foi instituído o Programa Mais Médicos, por meio da Medida Provisória (MP) $\mathrm{N}^{\mathrm{o}} 621$, de 08 de julho de $2013^{12}$, convertida na Lei $12.871^{13}$, cujos objetivos são: atender a necessidade por profissionais e ampliar as oportunidades de formação médica no Brasil. Integra o PMM o Projeto Mais Médicos para o Brasil (PMMB), que abrange as ações de provimento emergencial de médicos para municípios com escassez destes profissionais na Atenção Básica. Constituem o PMMB: o médico participante, o supervisor - profissional médico (CRM-Brasil) responsável pela supervisão profissional contínua e permanente do médico do Programa - e o tutor acadêmico. Outros atores institucionais também integram o PMMB, com vistas a apoiar e qualificar as atividades desenvolvidas no âmbito do Projeto, como os apoiadores institucionais.

Com vistas a qualificar o trabalho dos médicos do PMMB junto às equipes de saúde, foi previsto um amplo leque de ações educacionais ${ }^{17}$, dentre as quais está a Supervisão Acadêmica, exercida por médicos brasileiros, preferencialmente médicos de família e comunidade, os quais realizam visitas de supervisão periódicas (mensais) com o objetivo de conceder apoio técnico e pedagógico, na perspectiva de singularizar e potencializar a vivência e atuação dos médicos participantes, ofertando suporte para o desenvolvimento das ações da Atenção Básica ${ }^{18}$. 
Com o objetivo de fortalecer o apoio às ações do PMMB nos Estados, sobretudo aquelas relacionadas ao processo de Supervisão Acadêmica do Programa, a Diretoria de Desenvolvimento da Educação em Saúde da Secretaria de Educação Superior do Ministério da Educação (DDES/ $\mathrm{SESu} / \mathrm{MEC}$ ) estruturou uma proposta de apoio institucional, o qual teve início com a contratação de profissionais com o seguinte perfil: Experiência em Saúde Coletiva / Atenção Básica / Gestão do cuidado; Experiência em processos de formação (Educação Popular, Educação Permanente, PBL ou outras modalidades de formação construtivista); Experiência em Articulação/ apoio institucional e/ou matricial; movimentos sociais ou coordenação de equipe; Habilidade com informática.

Os primeiros estados a contarem com apoiadores foram Ceará (CE), Bahia (BA), Minas Gerais (MG) e Rio Grande do Sul (RS). Ao longo dos meses, a estratégia foi sendo ampliada de 04 para 12, depois 20, chegando ao total de 40 apoiadores em todas unidades federativas do País. Para dar suporte a esta nova equipe, a própria DDES necessitou modificar seu arranjo. Em 2014 foram realizadas 04 oficinas em Brasília, envolvendo o conjunto dos trabalhadores para planejamento e construção da estratégia do apoio. A Educação Permanente apresentou-se como eixo estruturante na construção/desconstrução/reconstrução do fazer dos atores em torno da supervisão acadêmica, até chegar ao modelo que orienta atualmente as atividades. Destes encontros foram construídos consensos sobre quem e o que é o apoio, que passou a ser chamado de AIMEC (Apoio Institucional do MEC) e que este fazer permanece em construção. Atualmenteo grupo vem desenvolvendo suas atividades perante um público de 1.941 supervisores e 201 tutores, vinculados a 51 Instituições Supervisoras $^{3}$.

O presente trabalho objetiva apresentar uma análise dessa proposta, a partir do relato do primeiro grupo de apoiadores (BA, CE, MG e RS) quanto às experiências de inserção nos territórios, articulação com os atores e instituições dos Estados, além dos pontos fortes, pontos frágeis e oportunidades de fortalecimento do papel do apoio institucional do MEC no PMMB. Vale destacar que esta experiência de apoio do PMMB é a primeira experiência de apoio institucional do MEC.

\section{Aspectos Metodológicos}

Trata-se de um relato das experiências do AIMEC nos estados da Bahia, Ceará, Minas Gerais e Rio Grande do Sul. As atividades de apoio nestes estados foram as primeiras experiências do apoio, e tiveram início em março de 2014.

Para a construção dos relatos de experiência, os quatro apoiadores sistematizaram o trabalho desenvolvido no âmbito do apoio ao Projeto Mais Médicos para o Brasil em seus respectivos estados, considerando o período de março/2014 a setembro/2015, tendo como base as seguintes questões norteadoras:

1) Como se deu sua apresentação no território de atuação? Houve auxílio de algum ator em especial?

3 Dados extraídos do sistema gerencial SIG Ebserh - http://sig.ebserh.gov.br/.

Tempus, actas de saúde colet, Brasília, 9(4), 49-66, dez, 2015.

ISSN 1982-8829 
2) Em quanto tempo você considera que as pessoas começaram a se reportar a você enquanto apoiador institucional do MEC?

3) Em quais atividades você foi se inserindo ao longo do tempo?

4) A sua participação nas atividades (no início do seu trabalho) foi mais ativa (planejamento/ coordenação/condução dos momentos) ou passiva (ouvinte)?

5) A depender da resposta anterior, você acha que com o tempo sua participação (de passiva para ativa, ou de ativa para mais ativa) sofreu mudanças? Se sim, a que atribui estas mudanças? Se não, porque você acha que não mudou?

6) Fazendo uma avaliação do seu tempo de atuação, em quais aspectos você acha que teve mais contribuição no PMMB em seu Estado? E no MEC?

7) Quais os pontos positivos e negativos de sua atuação enquanto apoiador institucional do MEC?

8) Quais oportunidades de melhoria/aprimoramento de sua atuação enquanto apoiador institucional do MEC você visualiza?

9) Quais as oportunidades de aperfeiçoamento pedagógico e de articulação político-institucional no âmbito do PMMB foram desenvolvidas em seu estado? Quais os pontos fortes e frágeis destes processos?

10) Quantos encontros locorregionais você organizou/auxiliou na organização em seu estado? Quais temáticas foram discutidas? Quais metodologias foram utilizadas? Foi feita alguma avaliação dos encontros locorregionais? Se sim, quais foram os resultados?

11) Quais as potencialidades, fragilidades e oportunidades que você visualiza na relação do Apoio Institucional PMMB-MEC com a tutoria e supervisão acadêmica?

Os relatos sistematizados são apresentados por estado na seção de resultados, e analisados na seção de Discussão.

\section{RESULTADOS}

Para viabilizar a execução das ações do Programa Mais Médicos pelo MEC, a estrutura organizacional da SESu/MEC foi alterada pelo Decreto $\mathrm{n}^{\mathrm{o}} 8.066 / 2013^{19}$, que criou a Diretoria de Desenvolvimento da Educação em Saúde (DDES), com duas coordenações: Coordenação Geral de Residências em Saúde e Coordenação Geral de Expansão e Gestão da Educação em Saúde, sendo esta última a responsável pela coordenação do PMMB. 
Para a execução do Projeto Mais Médicos para o Brasil, através da DDES, foi formado um grupo gestor, responsável pelo Módulo de Acolhimento e Avaliação e condução das ações da Supervisão Acadêmica. O grupo gestor iniciou suas atividades em outubro de 2013, contando com 05 integrantes que conduziram os três primeiros módulos de acolhimento e avaliação aos médicos intercambistas do Projeto.

Em 2014 foi instituída a coordenação executiva, com o objetivo de qualificar o processo de trabalho do grupo gestor, desenvolver mecanismos de avaliação e monitoramento para a supervisão acadêmica e implantar a estratégia do apoio institucional às instituições supervisoras do PMMB.

Através de processo seletivo foram selecionados pessoas para a) Apoio à Gestão: responsável pelo acompanhamento dos termos de cooperação entre MEC/ EBSERH / FIOCRUZ para pagamentos de diárias e passagens (logística das visitas de supervisão), pagamentos de bolsas de tutores, supervisores e núcleo gestor; e secretaria acadêmica dos módulos de acolhimentos e avaliação; b) Avaliação e Monitoramento: Responsável pelo acompanhamento dos indicadores de desempenho de tutores e supervisores e pelo tratamento das informações para compor informes e relatórios de gestão da diretoria; e c) Apoio e desenvolvimento: Responsável pela produção técnica de portarias, apresentações e manuais da supervisão acadêmica, e orientação às atividades dos tutores por meio do Apoio Institucional.

O Apoio Institucional é um arranjo de gestão utilizada em diferentes dimensões, organizações e com diferentes formatos. No MEC, o Apoio Institucional trata-se de uma estratégia para o fortalecimento da supervisão acadêmica, provendo suporte a tutores no planejamento, monitoramento da supervisão e na articulação com demais atores do projeto, além de: promover espaços de diálogo para a acompanhamento e articulação das ofertas pedagógicas do projeto, fortalecimento da atenção básica e da integração ensino-serviço, através da educação permanente. Refere-se a construção e o estabelecimento de um elo entre os atores envolvidos com a supervisão acadêmica, além de outros temas relacionados a articulação das ofertas pedagógicas, fortalecimento da atenção básica, implementação da política de educação permanente. Atualmente existem 40 Apoiadores distribuídos em todas as unidades da federação. Todos possuem experiência em processos formativos e em articulação institucional.

Em março de 2014, quando o AIMEC foi implantado, existiam 1.465 médicos atuantes no PMMB nos quatro estados, sendo acompanhados por 367 supervisores, os quais tinham seu processo trabalho coordenado por 29 tutores. Dados mais recentes (mês/referência: setembro/2015) mostram o crescimento destes quantitativos: 4.890 médicos, 638 supervisores, 68 tutores. A tabela 1 detalha estes quantitativos por Unidade Federativa. 
Tabela 1. Quantitativo de médicos, supervisores, tutores, IS e AIMEC por UF. Brasil, 2015.

\begin{tabular}{clccccc}
\hline UF & Período & Médicos & Supervisores & Tutores & IS $^{*}$ & AIMEC $^{* * *}$ \\
\hline Bahia & Mar/2014 & 383 & 80 & 07 & 02 & 01 \\
& Set/2015 & 1386 & 160 & 19 & 02 & 03 \\
Ceará & Mar/2014 & 644 & 122 & 08 & 06 & 01 \\
& Set/2015 & 1085 & 148 & 15 & 06 & 02 \\
Minas Gerais & Mar/2014 & 333 & 113 & 10 & 05 & 01 \\
& Set/2015 & 1318 & 181 & 20 & 05 & 03 \\
Rio Grande do & Mar/2014 & 105 & 52 & 04 & 04 & 01 \\
Sul & Set/2015 & 1101 & 149 & 14 & 05 & 03 \\
\hline
\end{tabular}

*IS: Instituições Supervisoras; **AIMEC: Apoio Institucional do MEC

\section{A experiência do AIMEC no estado da Bahia-Brasil}

A experiência no apoio institucional do MEC foi iniciada em março de 2014. Após a seleção para o cargo, a equipe de gestão central promoveu um Fórum de Articulação das Ofertas Educacionais do Projeto Mais Médicos para o Brasil, em Brasília/DF, onde estiveram presentes representantes dos tutores das Instituições Supervisoras de todos os Estados. Na ocasião os apoiadores pioneiros dos Estados da Bahia, Minas Gerais, Ceará e Rio Grande do Sul foram apresentados aos tutores presentes no evento, onde algumas agendas nos respectivos estados já foram pactuadas.

No caso da Bahia, dois dias após o evento foi realizado o I Encontro de Tutores e Supervisores do PMMB, onde o apoio foi apresentado e inserido no debate acerca das atividades do PMMB no Estado. Foi um momento importante, pois as dificuldades (desafios) e os avanços (facilidades ou potencialidades) vivenciados pelos supervisores e tutores em exercício foram apresentados e discutidos. Dessa forma, diversas possibilidades de atuação do apoio MEC foram vislumbradas e, inclusive, algumas agendas foram construídas.

A primeira impressão foi de um bom acolhimento dos atores presentes, sendo fundamental a parceria com o coordenador estadual do $\mathrm{PMMB}$, à época também tutor do PMMB, visto que este disponibilizou a agenda do PMMB no estado e dialogou sobre os diversos atores individuais e coletivos envolvidos na gestão e operacionalização do PMMB. Poucos dias depois, o trabalho do apoio MEC já era demandado tanto pelos tutores quanto por diversos supervisores, sobretudo o apoio na resolução de problemas relacionados às ajudas de custo (sistema FIOTEC) e recebimento de bolsas de supervisão atrasadas. A partir destas demandas, o apoio foi sendo pautado para outras pastas, sendo propostas reuniões periódicas para discussão das demandas e construção de atividades do PMMB.

O apoio participava de reuniões quinzenais com os tutores das IS, onde as principais demandas da 
Supervisão Acadêmica eram discutidas, e mensalmente das reuniões da Comissão de Coordenação Estadual (CCE), onde eram planejadas, monitoradas e avaliadas as atividades relacionadas ao PMMB no Estado, bem como discutidas as dificuldades e situações-problema identificadas nos municípios. Nestas reuniões, inicialmente, o papel do apoio era mais passivo, numa perspectiva de ouvinte, com o objetivo de apreender a realidade do PMMB no Estado, identificando possíveis parceiros e aliados, além de oportunidades de atuação. Com o passar do tempo, à medida que o apoio foi sendo reconhecido e legitimado entre os diversos atores do Estado, um papel mais ativo e protagonista foi sendo operacionalizado.

De início o apoio recebia (ouvia) as demandas e articulava junto à equipe de gestão central do PMMB-MEC a resolução dos problemas. Com isso, a legitimidade e reconhecimento do papel do apoio MEC foram se consolidando, o que permitiu um diálogo mais horizontal e construtivo. A partir de então as demandas passaram a ser discutidas numa perspectiva de 'mão dupla', onde os atores do Estado acionavam o apoio MEC e este acionava o Estado no tocante às demandas da gestão central do PMMB.

De uma forma geral, a partir da inserção do AIMEC no Estado da Bahia foram sendo percebidas melhorias nas atividades relacionadas à Supervisão Acadêmica, desde aspectos objetivos como o aumento da cobertura de supervisão, a partir do estímulo para a realização de reuniões regionais para captação de novos supervisores, até questões de cunho mais subjetivo, como o fomento a mudanças na relação entre tutores e supervisores. Com o trabalho do AIMEC, alguns movimentos começaram a ocorrer no Estado, como os encontros locorregionais, as reuniões entre tutores e supervisores e a articulação com a equipe do Telessaúde, atividades estas que até então não eram priorizadas e/ou não eram realizadas.

Com relação aos encontros locorregionais, no estado da Bahia foram realizados mais de $50 \mathrm{em}$ todas as 9 macrorregiões e 28 microrregiões de saúde no período de maio/2014 a setembro/2015. A organização destes encontros se deu das mais diversas formas: a) encontros planejados e executados com o apoio de todos os parceiros estaduais; b) encontros planejados e executados pelo grupo de tutores, supervisores e apoiadores MEC; c) encontros locorregionais com a participação exclusiva de médicos e supervisores; d) encontros locorregionais com participação de médicos do PROVAB; dentre outras.

Os encontros locorregionais foram inicialmente voltados à apreensão das dificuldades vivenciadas pelos médicos e/ou supervisores nos territórios de Atenção Básica dos municípios, na perspectiva de construir, coletivamente com os diversos atores ali presentes, estratégias de resolução dos problemas identificados. Com o passar do tempo, os encontros passaram a ter um cunho predominantemente pedagógico, onde foram debatidas diversas temáticas relacionadas ao processo de trabalho na Atenção Básica e no SUS e às demandas de aperfeiçoamento da clínica médica na Atenção Básica. Os participantes avaliaram os encontros de forma bastante positiva, afirmando que estes se configuravam como espaços de formação e de aproximação com os gestores 
dos municípios onde atuavam e com os gestores do PMMB no Estado.

De um modo geral, os principais pontos positivos do trabalho do AIMEC no Estado da Bahia neste período foram: a ampliação do AIMEC a partir de agosto de 2015, com a contratação de mais 3 apoiadoras, o que proporcionou a pulverização e capilaridade das ações do AIMEC em todo o estado; a boa articulação com os tutores e supervisores do PMMB; parceria com os atores da secretaria estadual de saúde (SESAB), sobretudo os atores da Superintendência de Recursos Humanos, Diretoria de Atenção Básica, Diretorias Regionais de Saúde e Escola Estadual de Saúde Pública (EESP), no desenvolvimento das atividades do PMMB; parceria com o Telessaúde, inclusive com participação dos representantes estaduais nos encontros locorregionais, a fim de disseminar o conhecimento sobre a utilização desta plataforma enquanto ferramenta de educação e qualificação do processo de trabalho de supervisores e médicos do PMMB; liberdade de atuação no Estado, tendo em vista a condução participativa e democrática da gestão central; bom suporte do núcleo gestor, por meio da equipe de apoio à gestão regional.

Por outro lado, pontos frágeis no trabalho do AIMEC também se mostraram neste período, dentre os quais podem ser destacados: necessidade de melhorias na comunicação e divulgação das ações; necessidade de maior aproximação e articulação do trabalho com as referências descentralizadas do Ministério da Saúde, com o intuito de alinhar as informações e demandas oriundas da gestão central de ambos os ministérios no que diz respeito à condução das ações do PMMB no estado; e necessidade de maior articulação com a EESP/SESAB, no sentido de dialogar e construir um processo de Educação Permanente voltado aos supervisores do PMMB.

Diante do exposto, a avaliação do trabalho do apoio MEC junto ao PMMB nos Estados tem se mostrado uma iniciativa bastante positiva, visto que fortalece e qualifica as ações, à medida que aproxima a gestão central das gestões estadual e municipal, numa perspectiva de trabalho articulado e colaborativo, necessário ao bom desempenho do PMMB.

\section{A experiência do AIMEC no estado do Rio Grande do Sul-Brasil}

O Apoio Institucional do MEC no Estado do Rio Grande do Sul foi apresentado no primeiro dia do módulo do $4^{\mathrm{o}}$ ciclo de acolhimento e avaliação de 298 médicos cooperados recém chegados ao estado. Estavam presentes representantes do Ministério da Saúde, OPAS, Coordenação Estadual, municipal e Instituições Supervisoras. O módulo teve duração de quatro semanas, contemplando aulas e avaliação de conteúdos relacionados à legislação do sistema de saúde brasileiro; ao funcionamento e atribuições do SUS, com ênfase na Atenção Básica em saúde; aos protocolos clínicos e atendimentos definidos pelo Ministério da Saúde; à língua portuguesa; e ao código de ética médica. Nesse momento o AIMEC se fez muito presente no papel de acolhimento dos médicos, na organização da distribuição dos espaços físicos de sala de aula, listas de presença, articulação e contato com os professores. Ainda não se tinha muito claro o papel do apoiador nessa conjuntura, mas não houve resistência a essa inserção por parte de outros atores, uma vez que a gestão estadual 
já trabalhava com uma lógica de apoio institucional para a atenção básica e tinha como prioridade o fortalecimento do PMMB no estado, logo o apoio do MEC viria a corroborar com isso.

O apoio logo iniciou sua participação em reuniões semanais junto aos representantes do Ministério da Saúde, do Estado e da assessora OPAS, assim como em reuniões da CCE, mas ainda de uma forma passiva, atento às discussões dos casos, percebendo o espaço e fazendo uma análise de conjuntura, o que foi muito importante para perceber as possibilidades e dificuldades colocadas no território para, a partir disso, poder atuar e se colocar de uma forma mais efetiva.

Uma das dificuldades encontradas no início foi a construção de vínculo com alguns tutores das Instituições Supervisoras, que seguiam operacionalizando os processos junto ao nível central do MEC e não legitimavam o apoio descentralizado como um ator importante para essa construção conjunta. $\mathrm{O}$ apoio era solicitado principalmente para a resolução de questões burocráticas dos entraves cotidianos como, por exemplo, problemas no pagamento de bolsas ou no sistema do Webportfólio (plataforma onde são executados os planos de trabalhos e postados os relatórios de supervisão).

No entanto, em alguns meses no território, o apoio foi ganhando espaço para outras construções e contribuições junto ao PMMB, especialmente em encontros Locorregionais das Coordenadorias Regionais de Saúde, promovidos pelo apoio institucional da gestão estadual da Atenção Básica, em parceria com os municípios. Mesmo que ainda não tão efetivamente junto aos tutores, essas experiências contribuíram muito para o acúmulo de bagagem e repertório dentro desse conjunto de vivências, em contato com médicos participantes do programa, gestores municipais e membros das equipes de Saúde da Família em diversas realidades do estado. Ter o apoio descentralizado (personificado) do Ministério da Educação nesses espaços contribuiu para um diálogo mais próximo com os municípios, aliviando algumas angústias sobre a articulação das ofertas pedagógicas do programa e monitoramento da supervisão acadêmica.

Ao longo desse processo, a equipe de Apoio Institucional descentralizada do MEC ganhou novos membros e, assim como em outros estados, o Rio Grande do Sul pôde contar com a chegada de mais duas pessoas, totalizando um número de três apoiadoras para a região, o que foi de extrema importância para o fortalecimento do processo de trabalho local.

O apoio passou a ser referenciado por Instituição Supervisora e seus respectivos tutores, afim de realizar um trabalho singular e cada vez mais próximo desses atores. A partir disso, iniciaramse pactuações de alinhamento dos fluxos de comunicação, organização e monitoramento da supervisão através de reuniões mensais entre apoio e tutoria, além de contatos feitos por outras vias de comunicação. Os principais pontos trabalhados nesses encontros diziam respeito à qualificação da supervisão acadêmica, suporte da tutoria aos seus respectivos supervisores, autonomia e responsabilidades das Instituições Supervisoras, qualificação das demandas encaminhadas a outras instâncias e encontros locorregionais. Nesse sentido, com diálogos mais próximos e afinados com 
as características da realidade dos territórios cobertos por essas instituições, o apoio pôde otimizar momentos de aperfeiçoamento pedagógico e articulação político-institucional através, também, de encontros de supervisão locorregional.

Esses encontros ocorreram numa periodicidade trimestral, com a presença dos médicos participantes do programa, tutores e supervisores de determinadas regiões, onde foram desenvolvidas atividades de educação permanente. Também puderam contar com a participação dos apoiadores do MEC, assim como gestores municipais e profissionais das unidades e redes de saúde dos diferentes territórios.

Eles aconteceram em diferentes formatos e metodologias. No Rio Grande do Sul já foram realizados encontros com um supervisor e seu grupo de médicos supervisionados, sendo de um ou mais municípios, outros com alguns supervisores e os médicos de uma determinada coordenação de saúde, assim como já ocorreram também dois grandes encontros reunindo todos os supervisores e médicos de uma Instituição Supervisora, contando também com a presença dos gestores das respectivas regiões de saúde. No entanto, esse último formato não era indicado ou nem mesmo possível no caso de instituições que abarcavam um grande número de supervisores. Além do que, percebeu-se que as locorregionais de menor porte apresentaram um nível de entrosamento e troca de experiências superior às demais, tornando o espaço mais potente e qualificado no que tange aos processos de aprendizagem e sensibilização da escuta mútua.

A construção metodológica e temática desses espaços se deu a partir da proposição de tutoria e supervisão, podendo ser pensada em conjunto com os médicos, a partir de suas necessidades e levando em conta também as características de cada região. No estado a maioria desses encontros foi realizada através de rodas de conversa, palestras com convidados externos, dinâmicas de grupo, discussão de casos, etc. As temáticas abordadas foram variadas, mas entre elas pôde-se destacar a saúde mental e hipermedicalização dos usuários como ponto de abordagem recorrente nesses encontros, por ser um assunto delicado e de difícil manejo na atenção básica comum a todas as regiões do estado. Também se destacou a importância do AIMEC nesses espaços de educação permanente para a divulgação e articulação com o Telessaúde como segunda opinião formativa, onde os médicos podem contar com o apoio de outros profissionais através de teleconsultorias, e-mail ou webconferência para o diagnóstico e tratamento na atenção básica, evitando encaminhamentos desnecessários, como por exemplo, no caso do telediagnóstico de doenças respiratórias, muito comuns no estado do Rio Grande do Sul devido à questões climáticas.

Pode-se dizer que o Apoio Institucional no estado trabalhou de forma integrada aos demais atores e atuou em consonância aos princípios preconizados pelo Programa, como atenção, cuidado, promoção à saúde e qualificação da atenção básica, através também da micropolítica e do trabalho vivo em ato no território. Operou a favor de um fazer coletivo, com articulação das ações pedagógicas, reforçando a aproximação entre teoria e prática na integração ensino-serviço,a fim de garantir e potencializar os espaços de educação permanente através da supervisão acadêmica. 


\section{A experiência do AIMEC no estado de Minas Gerais-Brasil}

A apresentação no território foi um desafio, a resistência de alguns atores em acolher um novo componente na equipe trouxe alguns desconfortos iniciais. Para superar essa dificuldade houve a parceria da tutoria de uma das instituições supervisoras e oreforço presencial de atores do núcleo gestor do MEC em muitos espaços, intensificando o papel desse novo representante da equipe, trazendo legitimidade. Foram necessários três meses para que se reportassem à figura do apoiador MEC no estado e no transcorrer desses meses foi sendo inserido como membro titular da CCE e na organização e participação de eventos do Projeto.

As participações nas agendas de reuniões no território inicialmente se deram de forma passiva como ouvinte, com o transcorrer do tempo essa postura foi se remodelando, tornando-se mais ativa, e hoje exerce um protagonismo diante das pautas previstas para o MEC no âmbito do território. Atualmente a figura do apoiador é extremamente demandada pelos diversos atores do Projeto e Programa Mais Médicos no Estado. Atribui-se essa mudançaao ganho de apropriação e governabilidade de alguns processos do território e até mesmo o modo de interagir com esses atores. Para abrir a possibilidade de diálogo, era preciso primeiro ser trabalhada a confiança e isso foi sendo realizado ao longo dos três primeiros meses.

Nessa perspectiva de consolidação do AIMEC no território de Minas Gerais, surgiu a necessidade de expandir essa figura de um para três apoiadores. Essa ampliação ocorreu em virtude da necessidade de aproximação entre as Instituições Supervisoras e o AIMEC, em uma unidade federativa com uma extensão territorial de $586.528 \mathrm{~km}^{2}$ e 853 municípios. Essa expansão possibilitou a articulação e o vínculo entre os diversos atores das instituições supervisores do PMMB,numa direção de construção democrática de agendas.A chegada desses dois novos componentes no território possibilitou alcançarmelhor enfrentamento do cenário de incertezas e conflitos advindos dessa fase inicial de consolidação e implantação do Projeto.

Em Minas Gerais existem cinco instituições Supervisoras e para a organização do processo de trabalho cada apoiador no estado se dividiu para apoiar uma ou duas IS.Os apoiadoresplanejavam as ações com seus tutores, definindo horários e tempo pré-determinado para realização de cada atividade da tutoria, tais como encontros entre Tutores e supervisores e Locorregionais, e tendo sempre o cuidado de manter um contato contínuo com a tutoria. Também mensalmente participavam das reuniões da CCE, que se tornou grande parceira na construção e consolidação do projeto no território mineiro. Feito isso, o apoio conseguiu nortear suas ações e sempre que imprevistos ocorriam no dia-a-dia, tinha-se o anteparo desses atores.

Atensão por parte dos tutores com a equipe do apoio foi sendo dissolvida, e essa figura tornouse um integrante do grupo; que buscou, de foram ativa e conjunta com as IS, estratégias e recursos diferenciados para dar continuidade e sustentabilidade ao projeto de forma qualificada, tendo em vista a promoção de espaços para Educação Permanente e a integração ensino-serviço. 
Uma ação de grande relevância no território foram os encontros locorregionais, quepossibilitaramespaços de aprendizado no formato de rodas de conversa entre gestores e profissionais do serviço, integrando as discussões e provocando alinhamentos na identificação dos principais desafios para a consolidação da Estratégia de Saúde da Família e refletindo sobre as potencialidades e fragilidades desse processo. Pode-se afirmar que à medida que esses encontros foram acontecendo no território, a proximidade entre tutor, supervisores, médicos supervisionados e gestoresaumentou e,proporcionalmente,fortaleceu as possibilidades de construção de processos de integração ensino-serviço, que propiciou a troca e o compartilhamento de descobertas antes não potencializadas.

O apoio Institucional no Estado potencializou e facilitou espaços de escuta,identificando as dificuldades e fragilidades, além de analisaraté que ponto essas estão relacionadas à forma de organização do território ou do núcleo gestor do projeto. Também possibilitou que a partir deste contato alguns objetivos institucionais pudessem ser articulados de forma mais participativa. Entretanto, o exercício do apoio ainda é um desafio, pois mediar o trabalho localmente depende, algumas vezes, da habilidade de envolver todos os atores nas atividades propostas e de utilizar diversas estratégias para manter o grupo aquecido.

Em síntese, a potencialidade do AIMEC em Minas Gerais se destacou em virtude do seu pertencimento ao território, exercendo um conhecimento mais amplo das necessidades e características do mesmo.

\section{A experiência do AIMEC no estado do Ceará-Brasil}

A construção do AIMEC no Ceará iniciou com a participação no Módulo de Acolhimento de Beberibe-CE, onde houve a recepção, momentos teóricos e avaliação dos 1.000 médicos cubanos que foram alocados em diversos Estados. Conseguiu-se, desde o início das atividades, trabalhar em equipe com as Referências Descentralizadas do Ministério da Saúde, o que impulsionou o AIMEC a ser bem recebido e compreendido desde os primeiros contatos.

A CCE se reunia mensalmente, o que fortaleceu a construção do programa no estado, e semanalmente promoveu reuniões da câmara técnica, cuja funcionalidade era reordenar processos e programar visitas, no intuito de resolver as situações-problema identificadas. Participavam assiduamente das reuniões representantes das diversas instituições envolvidas na gestão e operacionalização do PMMB no estado, como o COSEMS, a SESA/CE, o MEC, o MS, a tutoria das seis IS e a OPAS.

Após o Fórum ocorrido em Março/2014 em Brasília/DF, conseguiu-se inserção nas reuniões da CCE já a partir do mês de Abril /2014. Neste espaço a ideia do AIMEC foi explicitada a todos os atores, a qual foi bem recebida e compreendida por todos como um parceiro na construção do PMMB no Estado. Neste momento, agendou-se com todas as seis instituições supervisoras (Escola 
de Saúde da Família Visconde de Saboia; Escola de Saúde Pública do Ceará; Secretaria Municipal de Saúde de Fortaleza; Universidade da Integração Internacional da Lusofonia Afro-Brasileira; Universidade Federal do Cariri; e Universidade Federal do Ceará) e os 09 tutores do estado, momentos para compreender quais as atividades que estavam a desenvolver, que dificuldades tinham e repassar demandas enviadas pelo núcleo central acerca das visitas de supervisão não realizadas. Após a análise de conjuntura de cada IS e findadas as dificuldades iniciais, foram compartilhadas as reuniões entre tutores, reuniões entre tutores e supervisores, supervisões Locorregionais, reuniões com a Instituição responsável pela Especialização (NUTEDS/UFC) e Reuniões com o DSEI-CE.

Num processo de adaptação inicial, o AIMEC operou como figura mais passiva e ouvinte nas reuniões, e numa atuação mais ativa no planejamento das diretrizes com os tutores acerca da supervisão Locorregional no Ceará, na condução das reuniões entre AIMEC e Tutores (mensalmente), no aporte aos supervisores no manejo da plataforma da FIOTEC para solicitação de diárias e deslocamento, bem como na busca de integração e homogeneização dos atores no Ceará.

Dessa forma, o AIMEC contribuiu não somente na operacionalização do PMMB, através da diminuição de indicadores negativos (relatórios nãopostados, visitas não realizadas, bolsas não validadas), como em uma relação pedagógica de discussão, pactuação e criação de diretrizes para um aperfeiçoamento da Atenção Básica Brasileira, por meio de discussões sobre o trabalho em equipe, o processo de trabalho, o relacionamento interpessoal e o próprio aporte clínico nos encontros Locorregionais. Estes encontros, que conseguiram unir em um mesmo espaço tutores, supervisores, médicos do programa, gestores do SUS, coordenadores da Atenção básica, Representantes do MEC, MS, COSEMS, CCE, OPAS, despertaram, além dos processos formativos para os quais foram pensados, denúncias, ações, planejamento de visitas in loco e discussão de casos clínicos. Oportunizou-se o planejamento estadual e pactuações de diretrizes centrais das Locorregionais para que ocorressem trimestralmente.

A relação do AIMEC com a tutoria e supervisão acadêmica foi construída de maneira horizontal e coletiva, proporcionando o fomento e construção de 1) processos de avaliação no estado; 2) instrumentos para supervisão acadêmica; e 3) processos de formação de supervisores.

A figura do Apoiador, desde o início de suas ações, foi ressaltada como ponto positivo e ideia ímpar para o PMMB. No Ceará, durante processo avaliativo, foi destacado o empenho e a disponibilidade em solucionar situações que impossibilitam o fluxo regular do PMMB. Fora enfatizado, ainda, o feedback sempre em todas as solicitações, e-mails, mensagens, conversas e reuniões, o que demonstrou a seriedade de apoiar e homogeneizar as informações do núcleo central de Brasília às Instituições Supervisoras, demonstrando que apesar do pouco tempo de atuação, a ferramenta AIMEC vislumbra cumprir as pactuações realizadas com a implantação do PMMB. 


\section{DISCUSSÃO}

Considerando o caráter inovador do Programa Mais Médicos e a multiplicidade de realidades encontradas no país quanto ao que se entende por educação permanente, bem como os formatos de operacionalização do que foi preconizado pelo Programa, acreditamos que a própria estratégia da Educação Permanente,ao buscar promover espaços de escuta e compartilhamento de projetos, desejos, receios e dificuldades, operacionalizado pelo apoio institucional, conseguiu ocorrer e se instituir desde os primeiros momentos do AIMEC.

Por meio do contato com as instituições supervisoras, independente do formato que se deram (em espaços de poder, de troca de conhecimentos ou de compartilhamento de subjetividades), foi marca observável em todos os relatos uma postura de construção com os pares, em busca de resolução dos problemas encontrados pela supervisão acadêmica, seja no próprio grupo seja com a equipe central do programa.

Ao considerar que a educação permanente pressupõe impregnar de sentido o dia-a-dia do mundo do trabalho, tendo este como objeto de estudo para a mudança das práticas, podemos inferir que aheterogeneidade de vivênciaspossíveis por meio do AIMEC apresenta-se como uma rica fonte de matéria prima e objeto de trabalho para a equipe da DDES/SESu/MECconseguir uma maior aproximação com os territórios, o que permite a ampliação das possibilidades para promover uma melhor escuta para a construção desta política de forma mais alinhada às necessidades e características de cada região e, ao mesmo tempo, expande o olhar do ente federal quanto aos entraves existentes no território, informação esta que, em tempo adequado, aumentaa possibilidade de acertos na operacionalização da supervisão acadêmica e, consequentemente, fortalece as ações do Programa.

\section{CONSIDERAÇÕES FINAIS}

Diante do exposto, é possível afirmar que a implementação do apoio institucional doMEC dentro das atividades do PMMB tem sido uma experiência positiva e exitosa, sobretudo porque aproxima os três níveis de gestão (municipal, estadual e federal), favorece a resolução de problemas e circulação de informações de maneira rápida e segura, além de qualificar as atividades do PMMB através das experiências anteriores de trabalho e formação dos apoiadores.

No entanto, por ser uma experiência inovadora dentro do MEC, ainda enfrenta desafios, os quais se mostram como oportunidades de aperfeiçoamento desta ferramenta. Vale destacar que os encontros periódicos presenciais (em Brasília-DF) junto à gestão central têm minimizado as dificuldades encontradas na operacionalização do apoio nos estados, sobretudo por permitir a troca e compartilhamento de experiências e vivências.

O apoio institucional do MEC tem se apresentado como um novo e interessantemodo de gestão, e tem sido uma ferramenta de reconhecido valor junto aos demaisatores que constroem o PMMB 
nos Estados. Por meio do diálogo e trabalhocolaborativo característicos do AIMEC, resultados positivos têm sido observados, os quais têm impactado diretamente no aperfeiçoamento do PMMB, e direta ouindiretamente, na melhoria da APS e do sistema de saúde brasileiro.

\section{REFERÊNCIAS BIBLIOGRÁFICAS}

1. Paim JS. O que é o SUS? Rio de Janeiro: Editora FIOCRUZ, 2009.

2. Pinto, H.A.; Koerner, R. S.; Silva, D. C. A. Prioridade se traduz em mais e melhores recursos para a atenção básica. [Internet]. Brasília, DF: Rede de Pesquisas em Atenção Primária à Saúde, Associação Brasileira de Saúde Coletiva, 2012. Disponível em: $<$ http://www.rededepesquisaaps. org.br/2012/06/18/prioridade-se-traduz-em-mais-e-melhores-recursos-para-a-atencao-basica/ $>$ Acesso em: 29 dez 2014.

3. Brasil. Ministério da Saúde. Portaria GM no 3.066, de 23 de dezembro de 2008a. Define valores de financiamento do Piso da Atenção Básica Variável para a estratégia de Saúde da Família e Saúde Bucal, instituídos pela Política Nacional de Atenção Básica. Diário Oficial da União 24 dez de 2008; Seção 1

4. Brasil. Ministério da Saúde. Portaria n ${ }^{0}$ 154, de 24 de janeiro de 2008. Cria os Núcleos de Apoio à Saúde da Família - NASF. Diário Oficial da União 25 Jan de 2008; Seção 1.

5. Brasil. Ministério da Saúde. Portaria no 1.412, de 10 de julho de 2013. Institui o Sistema de Informação em Saúde para a Atenção Básica (SISAB). Diário Oficial da União 11 Jul de 2013; Seção 1.

6. Brasil. Ministério da Saúde. Portaria No 2.554, de 28 de outubro de 2011. Institui, no Programa de Requalificação de Unidades Básicas de Saúde, o Componente de Informatização e Telessaúde Brasil Redes na Atenção Básica, integrado ao Programa Nacional Telessaúde Brasil Redes. Diário Oficial da União 29 Out de 2011; Seção 1.

7. Pinto, H. A.; Sousa, A. N. A.; Ferla, A. A. O Programa Nacional de Melhoria do Acesso e Qualidade da Atenção Básica: várias faces de uma política inovadora. Saúde em Debate Out, 2014; 38(n. especial):358-72.

8. Brasil. Ministério da Saúde. Programa Nacional de Melhoria do Acesso e da Qualidade da Atenção Básica (PMAQ): Manual Instrutivo / Ministério da Saúde. Secretaria de Atenção à Saúde. Departamento de Atenção Básica. - Brasília: Ministério da Saúde, 2012. 138 p.

9. Brasil. Ministério da Saúde. Portaria GM nº 1.654, de 19 de julho de 2013. Institui, no âmbito do Sistema Único de Saúde, o Programa Nacional de Melhoria do Acesso e da Qualidade da Atenção Básica (PMAQ-AB) e o Incentivo Financeiro do PMAQ-AB, denominado Componente 
de Qualidade do Piso de Atenção Básica Variável - PAB Variável. Diário Oficial da União 10 Jul de 2013; Seção 1.

10. Brasil. Ministério da Saúde. Portaria GM no 2.488, de 21 de outubro de 2011. Aprova a Política Nacional de Atenção Básica, estabelecendo a revisão de diretrizes e normas para a organização da atenção básica, para a Estratégia Saúde da Família (ESF) e o Programa de Agentes Comunitários de Saúde (PACS). Diário Oficial da União 24 Out de 2011; Seção 1.

11. Brasil. Ministério da Saúde. Portaria Interministerial $n^{\circ} 2.087,1^{\circ}$ de setembro de 2011. Institui o Programa de Valorização do Profissional da Atenção Básica. Diário Oficial da República Federativa do Brasil, Poder Executivo, Brasília, DF, 2 set. 2011. Seção 1, p.92.

12. Brasil. Presidência da República. Casa Civil. Subchefia para assuntos jurídicos. Medida Provisória $\mathrm{N}^{\mathrm{o}}$ 621, de 8 de julho de 2013. Institui o Programa Mais Médicos e dá outras providências. Diário Oficial da União 09 Jul 2013; Seção1.

13. Brasil. Presidência da República. Casa Civil. Subchefia para assuntos jurídicos. Lei No 12.871, de 22 de outubro de 2013.Institui o Programa Mais Médicos, altera as Leis $n^{\circ} 8.745$, de 9 de dezembro de 1993, e n ${ }^{0}$ 6.932, de 7 de julho de 1981, e dá outras providências. Diário Oficial da União 23 Out 2013; 206: Seção1.

14. Carvalho MS, Sousa MF. Como o Brasil tem enfrentado o tema provimento de médicos? Interface (Botucatu) [Internet]. 2013; 17(47):913-26. Disponível em: http://www.scielo.br/pdf/ icse/v17n47/12.pdf Acesso em 30 set. 2015.

15. Oliveira FP, Vanni T, Pinto HA, Santos JTR, Figueiredo AM, Araujo SQ, Matos MFM, Cyrino EG. Mais Médicos: um programa brasileiro em uma perspectiva internacional. Interface (Botucatu) [online]. 2015, vol.19, n.54, pp. 623-634. Disponível em: http://www.scielo.br/pdf/icse/ v19n54/1807-5762-icse-19-54-0623.pdf Acesso em 30 set. 2015.

16. Organization for Economic Co-operation and Development. The Looming Crisis In The Health Workforce: How Can Oecd Countries Respond? OECD, 2008.

17. Ministério da Saúde (Brasil).Portaria Conjunta $N^{o} 1$, de 21 janeiro de 2014. Dispõe sobre o Módulo de Acolhimento e Avaliação de Médicos Intercambistas nas ações educacionais e de aperfeiçoamento desenvolvidas no âmbito do Projeto Mais Médicos para o Brasil. Diário Oficial da União 22 Jan 2014; Seção1.

18. Brasil. Ministério da Educação. Portaria No 585, de 15 de junho de 2015. Dispõe sobre a regulamentação da Supervisão Acadêmica no âmbito do Projeto Mais Médicos para o Brasil e dá outras providências. Diário Oficial da União 16 Jun 2015; Seção1. 
$66 / /$

19. Brasil. Presidência da República. Casa Civil. Subchefia para Assuntos Jurídicos. Decreto $\mathrm{n}^{\mathrm{o}}$ 8.066, de 7 agosto de 2013. Altera o Decreto $\mathrm{n}$-7.690, de 2 de março de 2012, que aprova a Estrutura Regimental e o Quadro Demonstrativo dos Cargos em Comissão do Ministério da Educação e remaneja cargos em comissão. Disponível em: http://www.planalto.gov.br/ccivil_03/ Ato2011-2014/2013/Decreto/D8066.htm Acesso em 13 out. 2015.

Artigo apresentado em 02-09-15 Artigo aprovado em 15-11-15 Artigo publicado no sistema em 30-12-15 